\title{
Urban systems: a socio-ecological system perspective
}

\begin{abstract}
Urban areas are hot spots of complex and dynamic interactions between society and ecosystems. Studies on such areas, however, have partially captured the coupled socio-ecological nature of urban environments. To address this gap, we examine the ways natural and social scientists have defined, developed and implemented research on urban environments. We discuss how these literatures set the foundation and explicitly advance urban studies through the lens of urban socio-ecological systems. By bringing these literatures together we forge a common ground between scholarly communities and foster cross-fertilization between researchers working on cities. A better understanding of the commonalities and differences of these disciplines in approaching urban environments is the first step toward opening corridors for new lines of discussions that better encompass the role played by urban socio-ecological systems in shaping changes and long-term sustainability.
\end{abstract}

Keywords: cities, environmental changes, socio-ecological systems, sustainability, urban areas
Volume I Issue | - 2017

\author{
Beatrice Frank,' Daisha Delano, ${ }^{2}$ Beth \\ Schaefer Caniglia ${ }^{3}$ \\ 'Department of Social Science, Capital Regional District of \\ Victoria, Canada \\ ${ }^{2}$ Department of Sociology, Oklahoma State University, USA \\ ${ }^{3}$ Department of Economics, Regis University, USA
}

Correspondence: Beatrice Frank, Department of Social Science, Capital Regional District of Victoria, Canada; Email frankbea@hotmail.com

Received: April 28, 2017| Published: June 0I, 2017

\section{Introduction}

Urban areas, consisting of cities and their surrounding hinterlands, have often been defined as static human built environments with high human populations and extensive impervious surface area. ${ }^{1}$ Yet, these areas are also centers of high productivity, play a part in determining social and ecological change, and influence economic growth rates of nations around the world. ${ }^{2-4}$ In the United States, for example, $37 \%$ of the national GDP of 2010 was produced by the top 30 cities in the country ${ }^{2}$ In Asia and the Pacific similar trends have been recorded by the UN, with cities hosting around $42 \%$ of the total population and generating $80 \%$ of the region's GDP..$^{5}$ Furthermore, "the process of urbanization characterizes contemporary societies, influences wellbeing, and in many ways increases both human and ecological vulnerabilities to environmental and climate change". In Africa and Asia, the fastest urbanizing continents today, ${ }^{4-6}$ the lack of infrastructure, services and preparedness for increasing human populations is leading to the sprawl of slums and informal settlements. ${ }^{7,4}$ In such urban areas, inequalities and poverty ${ }^{5,8}$ are magnified through social marginalization. ${ }^{8}$ And health insecurity. ${ }^{9,10}$ These vulnerabilities are enhanced by environmental overshoot and changing climate regimes. ${ }^{11,5}$ The conversion of natural areas and agricultural land through urban sprawl signifies economic growth and social welfare; however, it also deteriorates biodiversity, alters micro-climate patterns, erodes topsoil, diverts and interrupts water flows, and impacts the provisioning of many ecosystem services. ${ }^{6,12-14}$ The interactions and pressures caused by urban expansion on the environment go beyond the city and its surrounding urban areas. ${ }^{12,15}$ For instance, urban areas dominate the global demand for ecosystem services by using up to $60 \%$ of water resources for residential purposes, consuming $76 \%$ of wood for industrial production, generating over $50 \%$ of waste, and producing $60-80 \%$ of the world's greenhouse gas emissions. ${ }^{4,12,16}$ As emphasized by Grimm et al. ${ }^{17}$ "Urban areas are hot spots that drive environmental change at multiple scales". Hence, these areas are a central nexus for the long-term functioning of societies and ecosystems. ${ }^{12,15}$
Because of their dynamic socio-ecological nature, we see urban areas as human modified environments that encompass multiple levels, scales, processes and systems. These areas are increasingly drivers of change and novel ecosystems, "able to create challenges and offer opportunities for humankind's current and future resiliency and sustainability". ${ }^{1}$ Because of the many existing definition of resiliency and sustainability, we understand this term as follow. While resiliency is about coping and adapting to change, sustainability is about socio-natural relationships - specifically an "attempt to pacify the relationship between a society and its natural environment". ${ }^{18}$ Cities and their extended hinterland are ideal settings to research the linkages between people and nature, to better understand socioecological dynamics and responses to environmental modifications, and to identify what is needed to enhance both local and global resiliency and sustainability. ${ }^{6,11-15,19}$ Research on urban areas can provide a critical understanding of the direct or indirect influence of human built environments on societies, policy, and environmental practices. Nevertheless, studies on urbanities and global environmental change have not always been capable of capturing the coupled socioecological nature of cities and their surroundings. While scholars have recognized those urbanities' "structure, function, and dynamics are determined by coupled human-environment interactions", ${ }^{20}$ research on these areas has struggled to merge the ecological and social dimensions of urbanization. A synthesis of natural and social science research concerning urban areas is provided in this manuscript to portray the ways these lines of scholarship have developed and implemented research in urban areas, a key approach to set the foundation and inform future research on urban socio-ecological systems.

For the purpose of this paper, we will focus on subareas of urban studies that relate to urban socio-ecological systems. We acknowledge that research on urban areas goes beyond the work considered in this manuscript. Hence, the dimensions this paper looks at do not encompass all the features natural and social scientists have considered while exploring cities and their surrounding areas. 
Narrowing our study to specific dimensions of these scholarships is critical to provide a basis from which to build a more interdisciplinary, dynamic, and integrative understanding of urban socio-ecological systems. This approach represents a jumping off point to create a common ground for scholars of urban socio-ecological systems, to enhance cross-fertilization between researchers working on cities and to open up corridors for new lines of discussions that better encompass the role played by urban areas in shaping changes and long-term sustainability.

\section{Urban studies: a natural and social science perspective}

\section{Urban physical pattern}

In recent decades, studies on how natural processes are embedded in and influenced by urban areas have bloomed. ${ }^{11}$ The growing awareness that people and their living environments are an integral component of ecosystems as well as drivers of environmental change has led to the rise of research on urban areas and environmental interactions. ${ }^{19,15}$ Research in this domain has largely focused on biogeochemical cycles, ecological processes, and dynamic system frameworks. ${ }^{15,20-25}$ Questions about changes in morphology, distribution and abundance of ecosystems and organisms in and around cities, and on how these are affected by and have an effect on the human populations and the structure of cities have driven discourses on human-ecological systems interactions., ${ }^{21,22}$ Some of the major topics examined within this realm across geographical areas and scales have been: urban climates (i.e., urban heat islands, atmospheric accumulation, hydrology), urban soils (i.e., changes in soil composition, soil moisture, contamination, soil carbon, nitrogen dynamics), urban vegetation (i.e., species richness, heterogeneity of vegetation), urban biodiversity (i.e., composition, colonization, species richness, trophic dynamics) and urban biogeochemistry (i.e., nitrogen and carbon budgets, urban footprints, lawns and soil carbon, invasive species, biogeochemistry). ${ }^{14,15,20,26,27}$

While biophysical scientist have focused on ecosystems structures in cities, social scientists have looked at cities based on their social construction, and complex and variable definitions. ${ }^{26,28}$ Early studies in this domain have explored structures, processes, changes, and problems of cities and the interactions of citizens in human built environments. ${ }^{20,29}$ With the inclusion of principles of human ecology (e.g., ecological niche concept) and geography (e.g., land use concept), social science research has started to investigate the impact of the natural environment on urban life. For example, the positive effects of urban green spaces on the human population (i.e., health, physical activity, psychological well-being) and social cohesion have been explored. ${ }^{30-33}$ Others have examined "ecological gentrification", the process by which the creation of green spaces causes property values to increase forcing low-income residents to relocate. ${ }^{33}$ Some researchers have also explored the effects that humans have on the natural environment with the creation of vacant and abandoned lots, how past land use and vacancy affects urban areas, and what aspects of human well-being should be considered for the management of vacant urban lands. ${ }^{34}$ These ecologically driven urban studies have been influential in defining human-ecological interactions in cities.

\section{Urban spatiotemporal patterns}

Natural science research has centered its attention also on the complex forms, structures and transformations of urban areas. Some of the most important advances in this dimension include research on the spatiotemporal patterns of urbanization, spanning from urban growth and sprawl, to landscape uses and patterns. ${ }^{20,25,35}$ Urban agglomeration and landscape structural homogenization have increasingly concerned urban scholars. ${ }^{20}$ Hence, platforms with high visualization capacity, such as spatial analysis tools (e.g., Geographic Information Systems) and land use assessment models have been used to project future urban areas patterns and their impacts on the environment. ${ }^{20}$ The study of the organization, functioning, and development of cities has gone further by focusing on the processes, modes of regulation, and networks in and between metropolitan landscapes and on the effects of globalization across local, regional, national and international scales. $^{25,36-39}$ The idea behind categorizing cities in physical clusters across scales has been to exhibit the commonalities and divergences of urban areas. Such an understanding is key to addressing common problems of cities, such as energy consumption and its sustainability, multifunctional landscapes planning, green infrastructure design and cities carbon footprint in light of climate change. ${ }^{24,40}$

Debates on the spatiotemporal organization of cities have been paralleled by studies on variations in neighbourhoods' quality of life and wellbeing in and between cities. Researchers have expanded on issues of conflict and tension within urban areas, as well as cultural diversity, race and ethnic relations within cities. ${ }^{41-45}$ Metropolitan fragmentation, segregation and clustering based on socio-demographic features have been investigated to understand the distribution of socio-spatial inequalities in urban areas. ${ }^{36,46}$ The transnationalization of labour caused by the arrival of an international professional workforce and migrant workers has led to the formation of multinational identities and communities in cities. ${ }^{28}$ Neighbourhoods' social and demographic structures have been found to be created and reshaped by citizens' behavioural responses to city life (i.e., crowding, alienation, immigration, residential mobility). ${ }^{47}$ Thus social affiliation, residential situation, networks and human behaviours have become central themes while looking at the uneven distribution of opportunities in cities. ${ }^{47}$ Studies on mobility between and within cities (e.g., public transportation) and the physical distribution and access to services, such as hospitals, have also been explored in relation to social wellbeing. ${ }^{28,48-52}$

\section{Urban metabolism patterns}

Urban metabolism, or the process of material and energy production, flow and consumption in cities, is another important topic in urban studies used to investigate the infrastructure, energy efficiency, materials recycling, and waste management of urban ecosystems. Several frameworks have been developed to conceptualize urban metabolism and to assess the different flow pathways within and among cities (i.e., industrial metabolism, household metabolism, water metabolism, energy metabolism) Models of ecological analysis and ecological network analysis have been applied, for example, to analyze the structure, functioning and flows of urban systems. ${ }^{53,54}$ The ecological footprint concept has enabled scholars to link consumption with land use in urban areas, ${ }^{55}$ while environmental impact assessment approaches have allowed to evaluate the intensity of urban metabolism in specific cities. ${ }^{56}$ Urban areas with different metabolism have been compared to evaluate the efficiency in resource utilization and to identify criteria to assess the sustainability of a city. ${ }^{53,54,57}$ This concept has become instrumental for reporting the State of the Environment (SOE) and to suggest policies that maximize the efficient use of resources in urban settings. Hence, urban metabolism has been recognized as a fundamental tool to develop sustainable cities and communities. $^{53}$ 
While some researchers have specifically looked at urban sprawl, city development, and the impact on inequalities in urban areas, ${ }^{21,22,58,59}$ others have focused their attention on governance, the rights to urban spaces, and the relation between political injustice and cities..$^{28,60-66}$ Urban water, pollution, gentrification, food and ecological security, among other themes, have been explored in light of urban metabolism and power relations to understand the unevenness of urban areas. ${ }^{62,64,67}$ Contestation over water and the creation of uneven urban hydroscopes exemplifies how managing water supplies in cities often has been considered as a bio-political issue rather than an ecological matter. ${ }^{68,69}$ Hence, uneven power distribution and socio-natural interactions have been used as lenses to explore urban infrastructures, social cohesion and urban ecological security. ${ }^{62}$ Other studies on urban metabolism have instead focused on the lifestyle of urban residents and their ability to adapt to stressful urban conditions ${ }^{54}$ and on indicators to evaluate the livability of human built environments. ${ }^{53,54}$ Urban metabolism has enabled scholars to better portray the interconnection between urban ecosystems, the socio-natural processes that shape them, and power relations. This approach has thus become instrumental in showing "how urban environmental and social change co-determine each other and how these metabolic processes offer insights into creative pathways toward more democratic urban environmental politics". ${ }^{62}$

\section{Urban goods and services patterns}

Studies on urbanites have gone beyond describing urban ecosystems and their patterns by focusing on ecosystem goods and services and their influence on societies. For instance, the role played by urban green spaces and bodies of water in offering clean air, carbon sequestration and fresh water, among other services, has been widely explored. ${ }^{20,24,40,70-72}$ For example, researchers have focused on the role played by unsealed urban surfaces in moderating climate and preventing damages caused by floods through water flow regulation. ${ }^{73}$ A recent study proposes urban greening, or the creation of a green network that permeates a city, as a solution to alleviate disasters and urban impact on the environment. ${ }^{74}$ The provisioning, regulating, and supporting components of urban ecosystem services have become key topics in discourses about the transition toward global sustainability. This has not been the case for the last dimension of ecosystem services: cultural services. There have been some studies conducted regarding citizens' perceptions toward urban green spaces. ${ }^{75,76}$ While the spiritual, cognitive, recreational, aesthetic, cultural benefits and social influences of ecosystem services on humans have been identified as essential for society's wellbeing, these features of ecosystem services "have been least studied" and have not yet been fully explored in natural science. ${ }^{20}$ Furthermore, studies on urban ecosystem services have mostly centered on the benefits provided by ecosystem functions, their performance, and spatial distribution, and have ignored the number and distribution of citizens requiring these services (i.e., demand side) ${ }^{40,77}$ Such shortcomings have jeopardized the ability to fully understand the role played by urban ecosystem services in enhancing urban sustainability. ${ }^{77}$

Issues related to the economy, human wellbeing in cities, and political systems and institutions have been explored from a goods and services perspective. ${ }^{17,33,34,78}$ The historical evolution of capitalism, industrial restructuring and globalization, among others trends, have been deeply scrutinized to understand how social goods and services have and are flowing within and among urban areas. ${ }^{21,22,47}$ As stated by "Provisioning and access to businesses, and goods and services have become key themes in this area of study [social science]". The geography of consumption has affected multiple social dimension of cities and their hinterland, from access to the job market, to the migration across cities for better employment opportunities, to networking within and among urban areas, to housing affordability and neighbourhood gentrification, to international trade, global firms, markets and digital communication. . $^{21,28,36,39,47,79-82}$ "Globalization, indeed, has favoured the spatial dispersal of economic activities outside cities, enhanced urban areas centralization effects and emphasized the linkages binding these areas. Accordingly, a new economic configuration of urban areas has been described in urban studies, one that is more complex, trans-boundary and service intense". ${ }^{1}$

\section{Urban socio-ecological paradigm}

While not exhaustive, the overview provided offers an idea of the extensive work and the large contribution of biophysical and social science to urban studies. Complex, multi-scalar and interconnected urban areas no longer pertain to "the province of any one discipline". ${ }^{44}$ This is especially true when thinking about urban areas as nodes where transformations are economically, politically, socially and ecologically interwoven. As researchers have recognized that cities are dynamic, integrated and multi-scalar systems, a more widespread understanding of urban areas as human-driven ecosystems or socioecological systems has become common. ${ }^{19,20,83}$ Such an understanding has propelled a transition from focusing on the biophysical features of cities (i.e., ecology in the cities) to including the complex socioecological relationships of cities (i.e., ecology of cities) in urban studies. ${ }^{12,27,40,29}$ The ecology of cities, indeed, builds upon the city as a mosaic of land uses and management practices, subjected to biophysical (i.e., nutrients cycles, climate pattern, diversity distribution) and human (i.e., households, municipalities, agencies) driven influences and feedback loops. ${ }^{29}$ This concept emphasizes that urbanization alters the biophysical landscape and its functioning and quality, as much as it changes human behaviour, community structures and social organization.

Socio-ecological studies have largely embraced an interdisciplinary approach to provide insights to the multidimensional patterns and processes characterizing cities and their surrounding areas. ${ }^{44}$ The cross-fertilization between different disciplines has generated new and cutting edge research on urban areas. For instance, researchers have recently focused on coupled systems for downscaling climate projection models to specific cities in terms of urban sustainability. However, this work has begun to see too much emphasis on limited aspects of urban areas, arguing that a focus on climate models often ignores society's needs. ${ }^{84}$ With the recent development of the urban sustainability paradigm, which "identifies sustainability as the ultimate goal of studying cities", ${ }^{20}$ researchers have realized the need for an approach that considers landscape perspectives, interdisciplinary approaches, ecosystem services impact on human wellbeing, socio-ecological frameworks, and adaptive planning. ${ }^{20}$ Such an understanding is incentivizing natural science researchers to develop a more comprehensive toolkit for studying urban complex systems, one that better encompasses society's influence on urban areas. Overcoming sectorial thinking and approaches as well as better integrating the natural science dimension of urban areas in social science studies is thus fundamental to opening up corridors for new lines of discussion and propelling research on urban areas forward.

\section{Urban socio-ecological systems: toward an integrated approach}

The synergy between natural and social science research on urban 
areas becomes apparent in urban socio-ecological systems (SES) studies by the ${ }^{85}$ Define SES as a "coherent system of biophysical and social factors that regularly interact in a resilient, sustained manner; a system that is defined at several spatial, temporal, and organizational scales, which may be hierarchically linked; a set of critical resources (natural, socioeconomic, and cultural) whose flow and use is regulated by a combination of ecological and social systems; and a perpetually dynamic, complex system with continuous adaptation". For the development of strong theories on integrated urban systems, ${ }^{27}$ stresses the importance of using integrated socialbio-geophysical frameworks, considering the heterogeneity of systems and recommends drawing insights from hierarchy theory to organize and structure integrated approaches. An urban and ecological simulation modeling approach is instead proposed by ${ }^{86}$ to integrate the socio-ecological dimensions of urban areas. The integrated approach to long-term studies of urban ecological systems is instead proposed by. ${ }^{15}$ The authors suggest focal areas of study for social science and new approaches to better integrate socio-cultural factors into ecology studies. This early attempt to merge the ecological and social dimension of cities is followed by the ${ }^{24}$ description of cities as "complex socio-ecological systems (SES) that include people as the dominant species, other organisms, and a biotic elements, as well as the social and ecological contexts for these components" (p. 218). The authors go further by developing a conceptual model for urban SES using Phoenix as a case study to exemplify the interconnections and feedback loops between the ecological and social dimensions of the city. Based on the Baltimore Ecosystem Study (BES) and the District of Columbia-Baltimore City Urban Long-Term Ecological Research Area-Exploratory project, ${ }^{29}$ propose a blueprint for urban long term socio-ecological research based on three pillars:

i. Building site context by characterizing the historical background of the urban area.

ii. Modeling the spatial structure of cities by embedding the heterogeneous, multi-scalar complexity of SES.

iii. Structuring processes and maintenance activities through platforms that link science with decision making. ${ }^{87}$ Attempt to understand urban sustainability by modeling the transition from industrial cities, to sanitary cities to sustainable cities, using concepts from dominant literatures including sustainability, resilience, adaptation, and vulnerability. This model provides and understanding of the influence of inertia on city transition and sustainability; furthermore, their work attempts to build a transnational network between cities to facilitate sustainability research and promote projects with tangible solutions for various types of cities. As future research the authors propose to focus on the importance of transitioning from ecology of cities to ecology for cities by maintaining the goal of sustainability through the design, infrastructure and development phases. The pathways proposed by these researchers stress the need to understand urban SES trajectories by better merging socio-ecological interactions, integrating feedback loops and considering the past, present and possible future of urban systems.

It is not always the case that what works for one city in terms of increasing sustainability and resilience will work for another. Some research specifically acknowledges that the interactions and needs of stakeholders, planners, community members and others, vary dramatically between urban areas, and therefore different methods of increasing sustainability and resilience might be needed. ${ }^{88}$ Propose a "safe to fail" method for urban design that can be adopted and transformed based on the specific characteristics of the city in question. Broader use of these types of plans could benefit cities and prevent them from attempting to mimic the plans of another city that might not work in their own context.

Studies on socio-ecological systems and urban areas have also spanned a variety of themes, scales and geographical locations. ${ }^{89}$ For example, use an urban socio-ecological approach to link "humans and ecosystems in the context of African cultural values and heritage systems" (783). The socio-ecological functionality of green spaces along an urban gradient has been explored by ${ }^{83}$ in Karachi, Pakistan. The interaction between urban development, local ecosystems and green spaces in accordance with social-ecological principles has been the focus of a project developed in the Albano Resilient Campus, Stockholm. ${ }^{90}$ It has been also used as case study in a research using a social-ecological network model to address landscape and habitat fragmentation. ${ }^{91}$ The socio-ecological urban trajectories of the industrial eras have been explored by ${ }^{92}$ in Paris, France.

Other research has focused on individual ecological identity, human exemptionalism, anthropocentrism, and resource dependence in light of urban SES to explore positive attributes and characteristics of humans living in cities. ${ }^{93}$ Organised social-ecological innovation, understood as stakeholders management and collaborative governance of natural resources, has been used to explore the adaptive capacity and resiliency of urban SES. ${ }^{94}$ Governance and power relations have been also incorporated in urban forestry and greening in a special issue dedicated to social processes and the management of urban ecosystems. ${ }^{95}$ Gentrification and communities' empowerment, urban ecosystems and inequalities, marginalization and urban forests, social networks and urban food systems, power dynamics and urban parks, and non-human species and governance are the themes explored in this issue focused on urban social-ecological systems. The governance dimension is further synthesized in $^{96}$ where urban sustainability transitions are described in light of SES research.

The blooming of the socio-ecological approach in urban studies is illustrated by the diversity of frameworks and case studies borrowed from the SES literature and newly developed in urban studies to advance research and practices within this field. Urban SES approaches are flourishing through projects such as Urban Biodiversity and Ecosystem Services (URBES). Furthermore, cities lab (e.g., Cities and Biodiversity Outlook, Urban Ecology City Lab, Urban Ecology Research Lab) and institutes (i.e., Stockholm Resilience Center, The Beijer Institute of Ecological Economics) are emerging across the world. Interest in urban SES is also demonstrated by the rise of interdisciplinary networks and teams (e.g., Urban Biosphere Network-URBIS), blogs (i.e., the nature of cities), tools (i.e., urban planet), atlas (and project proposals (i.e., San Juan Ultra). ${ }^{19,6}$ This diversification in urban SES research further emphasizes the unique momentum this field is experiencing.

\section{Future directions}

Urban areas are increasingly the primary human inhabited ecosystems; they dominate demand for natural resources and determine local to global changes. To better understand the role played by these human built socio-ecological systems in shaping environmental changes and long-term sustainability, there are three major areas that need to be further discussed in urban studies: 


\section{Integration between natural and social science research}

While maintaining their disciplinary foci, natural and social science disciplines have increasingly been combined in urban studies. As shown from the blooming literature on urban SES, embracing an interdisciplinary approach has been recognized as key for developing a perspective from which to explore how urban built ecosystems, and their complex and broad-ranging connections can help communities to become more sustainable. ${ }^{44,28}$ From this standpoint, merging natural and social science insights has offered new perspectives about the urban socio-ecological environment, especially in regards to leveraging research on themes that have already represented common interest and concern in urban studies. Research on urban metabolism exemplifies domain in which natural and social science have found strong points of convergence. Scholars have linked mechanisms concerning material and energy production, flow and consumption with social theories, quality of life and power distribution in cities. ${ }^{97,98}$ While many themes, frameworks, methodologies, and analytical approaches are shared by natural and social sciences in urban study research, others have themes that remain unique and limited to the scholarship considered. For example, cultural ecosystem services have been described by ${ }^{20}$ as "least studied" and "yet to be fully explored" in natural science. Nevertheless, a vast literature on the impact that the urban natural environment has on citizens exists in social science. ${ }^{30-34}$ Limitations in using findings generated by other disciplines may jeopardize the ability to:

i. obtain a holistic overview of the linkages between people and nature;

ii. better understand socio-ecological dynamics and responses to environmental modifications;

iii. identify what is needed to enhance both local and global urban sustainability.

While maintaining their interests in discipline-specific aspects of urban systems, natural and social scientists should more thoroughly consider what type of urban research has been conducted in other disciplines. By going beyond the disciplinary focus of a specific scholarship-an issue shared with other interdisciplinary disciplinesit is possible to identify the overlap with other fields, and thus create a more holistic approach toward studying urban areas and their socioecological dimensions. By offering to scholars a better understanding of how different disciplines have investigated urban areas, this paper creates jumping off point from which to further discuss the synergies and divergences between natural and social science research in urban studies. Such an understanding is compelling in an increasingly urbanizing context where cities need more urgently to become sites of sustainability and resource efficiency for the long-term maintenance of socio-ecological wellbeing.

\section{Miss-match between spatiotemporal scales}

Creating a common ground between disciplines can be difficult if a shared understanding of the spatiotemporal feature influencing urban areas are lacking. Often, challenges between natural and social science researchers arise as the time line and the geographical scale at which urban areas are explored diverges between disciplines. While natural scientists may focus on long-term and broad scale urban processes influenced by historical events, social scientists often center their attention on current, short-term and fine scale urban issues. Hence, the scale at which urban ecosystems respond to changes might not align with the one at which urban society can influence decision-making processes and policy. Furthermore, when considering increasing globalization and interconnection between urban environments across the world, it becomes even more difficult to target research to a spatiotemporal scale that fits both natural and social scientists. This miss-match in scale of urban socio-ecological observation and processes creates ambiguity, often reducing the ability of researchers to combine information coming from natural and social science research into urban studies. To overcome this constraint, acknowledging and defining timeframes, geographical scale and boundaries of urban areas is key. Future research should therefore focus on better defining the meaning of urban areas and on modeling how to account for the spatiotemporal miss-match between natural and social science processes and observations. Understanding that a web of past, present and future connections and interactions exist within and between cities can help in better encompassing the role played by natural and social forces in shaping environmental changes and in influencing the long-term sustainability of urban areas.

\section{Vocabulary of urban socio-ecological systems}

Another barrier to the development of a common ground between natural and social science in urban studies is the lack of a vocabulary, or toolkit, that helps cross-disciplinary boundaries, enhance collaborations, and foster reciprocity between scholarships. Concepts, theories, frameworks and applied approaches have been borrowed from one discipline to address problems raised in other fields of urban studies. The transfer of such vocabulary, however, has not always resulted in cross-fertilization between disciplines. To implement interdisciplinary approaches in urban studies, shared definitions and approaches are needed. Attempts to define terms from an interdisciplinary perspective have been made, as in the case of resilience. ${ }^{99}$ Projects like HIVE (Helping Interdisciplinary Vocabulary Engineering) are providing frameworks to enhance the integration of data repositories, libraries, and archives across multiple disciplines. ${ }^{100}$ As emphasized by. ${ }^{101}$ When "certain terms become more broadly applicable, there is more cross-communication between disciplines."

While this three overarching outlooks - lack of integration between natural and social research, miss-match between spatiotemporal scales and lack of a common vocabulary- have been specifically discussed in light of urban areas, common challenges can be encountered in other interdisciplinary disciplines. Researchers that look at issues from multiple discipline perspective can benefit from the above outlooks and should consider pathways to take advantage and acquire a common meaning of concepts, theories, frameworks and applied approaches across disciplines. By developing a shared toolkit it will be possible to understand the linkages between people and nature, capture the coupled socio-ecological foundation of systems beyond the urban areas, and better merge the ecological and social dimensions of interdisciplinary research.

Urban SES studies are rapidly evolving and moving in new directions, creating the need to further develop the definitions, vocabulary, and toolkit of knowledge available to urban scholars. Rethinking what urban areas are and how to move toward a more holistic socio-ecological system approach to understanding their processes will be indeed the main challenge urban scholars will encounter while establishing new paths and processes that helps enhance both local and global socio-ecological capacity to respond and adapt to change. For a transition toward societies and ecosystems 
characterized by long-term resilience and sustainability, there is an urgent need to build upon the urban SES momentum by better including and expanding the interdisciplinary socio-ecological literature on urban areas. Only by further developing an integrated and system approach, cities might become sites of sustainability and resource efficiency.

\section{Acknowledgments}

We wish to thank: Rebecca Sheehan and Heather R. McCarthy for their support in the paper writing process.

\section{Funding}

This work was supported by the National Science Foundation (NSF) and EPSCoR under Grant "Adapting Socio-ecological Systems to Increased Climate Variability" (\#IIA-1301789).

\section{Conflict of interest}

The author declares no conflict of interest.

\section{References}

1. Canigilia B, Vallee M, Frank B. Resilience, Environmental Justice \& the City. United Kingdom: Routledge; 2017. 254 p.

2. Manyika J, Remes J, Dobbs R, et al. Urban America: US cities in the global economy. USA; 2012.

3. Polèse M. Cities and national economic growth: a reappraisal. Urban Studies. 2005;42(8):1429-1451.

4. The Asia-Pacific issue brief series on urbanization and climate change. UNEP. 2012.

5. State of Asia Cities 2010/11. Fukuoka: UN-HABITAT. 2010.

6. Schewenius M, McPhearson T, Elmqvist T. Opportunities for increasing resilience and sustainability. Ambio. 2014;43(4):434-44.

7. Ooi GL, Phua KH. Urbanization and slum formation. J Urban Health. 2007;84(Suppl 1):27-34.

8. Understanding urban inequalities in Bangladesh: a prerequisite for achieving vision 2021. A study based on the results of the 2009 multiple indicator cluster survey. Evergreen Printing \& Packaging: UNICEF Bangladesh; 2010.

9. Jorgenson AK, Rice J. Urban slums and children's health in less developed countries. American Sociological Association. 2012;18(1):103-116.

10. Riley LW, KO AI, Unger A, et al. Slum health: diseases of neglected populations. BMC International Health and Human Rights. 2007;7:2.

11. Catton WR. Overshoot: The ecological basis of revolutionary change. Champaign: University of Illinois Press. Public Health Rep. 1982;124(1):167-168.

12. Elmqvist T, Fragkias M, Goodness J, et al. Stewardship of the biosphere in the urban era. In: Elmqvist T, et al. editors. Urbanization, biodiversity and ecosystem services, challenges and opportunities. USA: Springer; 2013. p. 719-747.

13. Grove MJ. Cities: managing densely settled social-ecological systems. In: Folke C, et al. editors. Principles of ecosystem stewardship. USA: Springer; 2009. p. 281-294.

14. Pickett STA, Cadenasso ML, Grove MJ, et al. Urban ecological systems: scientific foundations and a decade of progress. Journal of Environmental Management. 2011;92:331-362.
15. Grimm NB, Grove MJ, Pickett STA, et al. Integrated approaches to longterm studies of urban ecological systems. In: Marzluff J, et al. editors. Urban ecology an international perspective on the interaction between humans and nature. USA: Springer; 2008. p. 143-160.

16. Kattel GR, Elkadi H, Meikle H. Developing a complementary framework for urban ecology. Urban forestry and urban greening. 2013;12:498-508.

17. Grimm NB, Faeth SH, Golubiewski NE, et al. Global change and the ecology of cities. Science. 2008;319:756-760.

18. Arias-Maldonado M. The Anthropocenic turn: Theorizing sustainability in a post natural age. Sustainability. 2016;8(10):1-17.

19. Anderson P, Elmqvist T. Urban ecological and social-ecological research in the city of Cape Town: insights emerging from an urban ecology City Lab. Ecology and Society. 2012;17(4):23.

20. Wu J. Urban ecology and sustainability: the state-of-the-science and future directions. Landscape and Urban Planning. 2014;125:209-221.

21. Aguilar AG. Urban Geography. In: Sala M, editor. Encyclopaedia of life support systems (EOLSS), UNESCO: Geography - volume II. Oxford: Eolss Publishers; 2009. p. 127-140.

22. Hall T, Barrett HL. Urban geography. 4th ed. UK: Routledge; 2012.

23. Kaplan D. Urban geography. 2nd ed. USA: John Wiley \& Sons; 2009.

24. Grimm NB, Redman CL, Boone CG, et al. Viewing the urban socio-ecological system through a sustainability lens: lessons and prospects from the central Arizona-Phoenix LTER programme. In: Singh SJ, et al. editors. Long term socio-ecological research: studies in society-nature interactions across spatial and temporal scales. USA: Springer; 2013. p. 217-247.

25. Pacione M. Urban geography: A global perspective. 2nd ed. USA: Routledge; 2005.

26. McIntyre NE, Knowles-Yánez K, Hope D. Urban ecology as an interdisciplinary field: differences in the use of "urban" between the social and natural sciences. In: Marzluff J, et al. editors. Urban ecology an international perspective on the interaction between humans and nature. USA: Springer; 2008. p. 49-71.

27. Pickett STA, Cadenasso ML, Grove MJ, et al. Urban ecological systems: linking terrestrial ecological, physical, and socioeconomic components of metropolitan areas in urban ecology an international perspective on the interaction between humans and nature. In: Marzluff J, et al. editors. Urban ecology an international perspective on the interaction between humans and nature. USA: Springer; 2008. p. 99-123.

28. Sassen S. Urban sociology in the $21^{\text {st }}$ century. In: Bryant CD, Peck DL, editors. $21^{\text {st }}$ century sociology. USA: Sage Publications; 2008. p. 476 486.

29. Grove MJ, Pickett STA, Whitmer A, et al. Building an urban LTSER: the case of the Baltimore ecosystem study and the D.C./B.C. ULTRA-Ex Project. In: Singh SJ, et al. editors. Long term socio-ecological research: studies in society-nature interactions across spatial and temporal scales. USA: Springer; 2013. p. 369-409.

30. Barbosa O, Tratalos JA, Armsworth PR, et al. Who benefits from access to green space? A case study from Sheffield, UK. Landscape and Urban Planning. 2007;83(2007):187-195.

31. Iverson LR, Cook EA. Urban forest cover of the Chicago region and its relation to household density and income. Urban Ecosystems. 2001;4(2):105-124.

32. Jennings V, Johnson CG, Schulterbrandt RG. Promoting environmental justice through urban green space access: asynopsis. Environmental Justice. 2012;5(1):1-7. 
33. Wolch JR, Byrne J, Newell JP. Urban green space, public health and environmental justice: the challenge of making cities 'just green enough'. Landscape and Urban Planning. 2014;125:234-244.

34. Nassauer JI, Raskin J. Urban vacancy and land use legacies: a frontier for urban ecological research, design, and planning. Landscape and Urban Planning. 2014;125:245-253.

35. Zeng C, Liu Y, Qui L. Urban sprawl and related problems: Bibliometric analysis and refined analysis from 1991 to 2011. Chinese Geographical Science. 2014;24(2):245-257.

36. Da Cunha A, Mager C, Matthey L, et al. Urban geography in the era of globalization: the cities of the future emerging knowledge and urban regulations. Geographica Helvetica. 2012;67:67-76.

37. Kraas F. Megacities and global change: key priorities. The Geographical Journal. 2007;173(1):79-82.

38. Rozenblat C. Opening the black box of agglomeration economies for measuring cities' competitiveness through international firm networks. Urban Studies. 2010;47(13):2841-2865.

39. Spencer JH. Globalization and Urbanization. USA: Rowan \& Littlefield; 2015. $268 \mathrm{p}$.

40. Breuste J, Qureshi S, Junxiang L. Applied urban ecology for sustainable urban environment. Urban Ecosystems. 2013;16(4):675-680.

41. Du Bois WEB. The environment on the negro. In: Lin J, Mele C, editors. The urban sociology reader. UK: Routledge Urban Reader Series; 2012 p. 174-182.

42. Flanagan WG. Urban sociology: Images and structure. USA: Allyn \& Bacon; 1999.

43. Lin J, Robinson P. Spatial disparities in the expansion of the Chinese etnobutb of Los Angeles. In: Lin J, Mele C, editors. The urban sociology reader. UK: Routledge Urban Reader Series; 2012. p. 174-182.

44. May T, Perry B, Le Galès P, et al. The future of urban sociology. Sociology. 2005;39:343-370.

45. May T, Perry B. Continuities and change in urban sociology. The future of urban sociology. Sociology. 2008;39(2):343-347.

46. Joassart-Marcelli P. Gender, social network geographies, and low-wage employment among recent Mexican immigrants in Los Angeles. Urban Geography. 2014;35(6):822-851.

47. Knox P, Pinch S. Urban social geography: an introduction. 6th ed. UK: Pearson Education Limited; 2010.

48. Addie JD. Metropolitics in motion: The dynamics of transportation and state reterritorialization in the Chicago and Toronto city-regions. Urban Geography. 2013;34(2):188-217.

49. Bissell D. Passenger mobilities: affective atmospheres and the sociality of public transport. Environment and Planning D: Society and Space. 2010;28(2):270-289.

50. Comber AJ, Brunsdon C, Radburn R. A spatial analysis of variations in health access: linking geography, socio-economic status and access perceptions. Int J Health Geogr. 2011;10:44

51. French KN. Patterns and consequences of segregation: An analysis of ethnic residential patterns at two geographic scales. 2008.

52. Sheller M, Urry J. The new mobilities paradigm. Environment and Planning. 2006;38:207-226.

53. Kennedy C, Pincetl S, Bunje P. The study of urban metabolism and its applications to urban planning and design. Environ Pollut. 2011;159(89):1965-1973.

54. Zhang Y. Urban metabolism: A review of research methodologies. Environ Pollut. 2013;178:463-473.
55. Dakhia K, Berezowska-Azzag E. Urban institutional and ecological footprint: a new urban metabolism assessment tool for planning sustainable urban ecosystems. Management of Environmental Quality: An International Journal. 2010;21:78-89.

56. Liu GY, Yang ZF, Chen B, et al. Monitoring trends of urban development and environmental impact of Beijing, 1999e2006. Sci Total Environ. 2011;409(18):3295-3308.

57. Spaargaren G, Mol APJ, Buttel FH. Governing Environmental Flows: Global Challenges to Social Theory. USA: The MIT Press; 2006.

58. Elliot JR, Pais J. Race, class, and hurricane Katrina: social differences in human responses to disaster. Social Science Research. 2006;35(2):295321

59. Jaret C, Ruddiman EP, Phillips Kurt. The legacy of residential segregation. In: Bullard R, et al. editors. Sprawl city: race politics and planning in Atlanta. USA: Island Press; 2000. p. 111-138.

60. Collins TW. Marginalization, facilitation, and the production of unequal risk: the 2006 Paso del Norte Floods. Antipode. 2010;42(2):258-288.

61. Harvey D. The right of the city. In: Lin J, Mele C, editors. The urban sociology reader. UK: Urban Reader Series, Routledge; 2012. p. 174 182.

62. Heynen N. Urban political ecology I:the urban century. Progress in Human Geography. 2014;38(4):598-604.

63. Holifield R. Actor-network theory as a critical approach to environmental justice: a case against synthesis with urban political ecology. Antipode. 2009;41(4):637-658

64. Loftus A. Everyday environmentalism: creating an urban political ecology. USA: University of Minnesota Press; 2012.

65. Merry SE. Spatial govern mentality and the new urban social order: controlling gender violence trough law. In: Lin J, Mele C, editors. The urban sociology reader. UK: Routledge Urban Reader Series; 2012. p. 174-182.

66. Sheehan R. 'I'm protective of this yard': long-term homeless persons' construction of home place and workplace in a historical public space. Social and Cultural Geography. 2010;11(6):539-558.

67. Gabriel N. Urban political ecology: environmental imaginary, governance, and the non-human. Geography Compass. 2014;8(1):3838

68. Budds J. Contested $\mathrm{H}_{2} \mathrm{O}$ : Science, policy and politics in water resources management in Chile. Geoforum. 2009;40(3):418-430.

69. Bakker K. Constructing 'public' water: The World Bank, urban water supply, and the biopolitics of development. Environment and Planning D: Society and Space. 2013;31(2):280-300.

70. Bolund P, Hunhammar S. Ecosystem services in urban areas. Ecological Economics. 1999;29:293-301.

71. Lundy L, Wade R. Integrating sciences to sustain urban ecosystem services. Progress in Physical Geography. 2011;35(5):653-669.

72. Pataki DE, Carreiro MM, Cherrier J, et al. Coupling biogeochemical cycles in urban environments: Ecosystem services, green solutions, and misconceptions. Frontiers in Ecology and the Environment. 2011;9(1):27-36

73. Haase D. Holocene floodplains and their distribution in urban areas functionality indicators for their retention potentials. Landscape Urban Plan. 2003;66(1):5-18.

74. Jim CY. Sustainable urban greening strategies for compact cities in developing and developed economies. Urban Ecosystems. 2013;16(4):741-761. 
75. Qureshi S, Breuste JH, Jim CY. Differential community and the perception of urban green spaces and their contents in the megacity of Karachi, Pakistan. Urban Ecosystems. 2013;16(4):853-870.

76. Perelman P, Breuste J, Madanes Y, et al. Use of visitors' perception in urban reserves in the Buenos Aires metropolis. Urban Ecosystems. 2013;16(4):841-851.

77. Breuste J, Qureshi S. Urban sustainability, urban ecology and the Society for Urban Ecology (SURE). Urban Ecosyst. 2011;14(3):313-317.

78. Buyantuyev A, Wu J. Urbanization alters spatiotemporal patterns of ecosystem primary production: a case study of the Phoenix metropolitan region. Journal of Arid Environments. 2009;73:512-520.

79. Romero V, Solís E, De Ureña JM. Beyond the metropolis: new employment centers and historic administrative cities in the Madrid global city region. Urban Geography. 2014;35(6):889-915.

80. Short JR, Yeong-Hyun K. The global urban system. In: J Short JR, Yeong-Hyun K, editors. Globalization and the city. USA: The University of Michigan; 1999. p. 24-57.

81. Stenning A, Smith A, Rochovska A, et al. Credit, debt, and everyday financial practices: low-income households in two post socialist cities. Economic Geography. 2010;86(2):119-145.

82. Walks A. Mapping the urban debtscape: the geography of household debt in Canadian cities. Urban Geography. 2013;34(2):153-187.

83. Qureshi S, Breuste JH, Lindley SJ. Green space functionality along an urban gradient in Karachi, Pakistan: a socio-ecological study. Human Ecology. 2010;38(2):283-294.

84. Daron JD, Sutherland K, Jack C, et al. The Role of Regional Climate Projections in Managing Complex Socio-ecological Systems. Regional Environmental Change. 2015;15(1):1-12.

85. Redman CL, Grove MJ, Kuby LH. Integrating social science into the long-term ecological research (LTER) network: social dimensions of ecological change and ecological dimensions of social change. Ecosystems. 2004;7(2):161-171.

86. Alberti M. Modeling the urban ecosystem: a conceptual framework. In Marzluff J, et al. editors. Urban ecology an international perspective on the interaction between humans and nature. New York, USA; 2008. p. 623-646.

87. Childers DL, Pickett STA, Grove MJ, et al. Advancing Urban Sustainability Theory and Action: Challenges and Opportunities. Landscape and Urban Planning. 2014;125:320-328.

88. Ahern J, Sarel C, Niemela J. The Concept of Ecosystem Services in Adaptive Urban Planning and Design: A Framework for Supporting Innovation. Landscape and Urban Planning. 2014;125:254-259.
89. Barau AS, Ludin ANM, Said I. Socio-ecological systems and biodiversity conservation in African city: insights from Kano Emir's Palace gardens. Urban Ecosyst. 2013;16:783-800.

90. Barthel S, Colding J, Erixon H, et al. Principles of social-ecological urbanism-case study: Albano campus, Stockholm. Sweden: Trita-ARK Forsknings publikationer; 2013.

91. Xiu N, Ignatieva M, Chai Y, et al. A socio-ecological perspective of urban green networks: the Stockholm case. Urban Ecosystems. 2017;20(4):729-742.

92. Barles, Sabine. The main characteristics of urban socio-ecological trajectories: Paris (France) from the $18^{\text {th }}$ to the $20^{\text {th }}$ century. Ecological Economics. 2015;118:177-185.

93. Tidball KG, Stedman R. Positive dependency and virtuous cycles: from resource dependence to resilience in urban social-ecological systems. Ecological Economics. 2013;86:292-299.

94. Dennis M, Armitage RP, James P. Social-ecological innovation: adaptive responses to urban environmental conditions. Urban ecosystems. 2016;19(3):1063-1082.

95. Campbell LK, Gabriel N. Power in urban social-ecological systems: Governance, knowledge production, and marginalization. Journal Urban Forestry \& Urban Greening. 2017;19.

96. Muñoz-Erickson TA, Campbell LK, Childers DL, et al. Demystifying governance and its role for transitions in urban social-ecological systems. Ecosphere. 2016:7(11).

97. Lennox J, Turner G. State of the environment report on human settlements: stocks and flows indicators. In: Technical report CSIRO Sustainable Ecosystems. Prepared for the 2006 Australian State of the Environment Committee. Australia; 2004. 159 p.

98. Schiller F. Linking material and energy flow analyses and social theory. Ecological Economics. 2009;68(6):1676-1686.

99. Caniglia BS, Frank B, Delano D, et al. Enhancing environmental justice research and praxis: the inclusion of human security, resilience and vulnerabilities literature. International Journal of Innovation and Sustainable Development. 2014;4:409-426.

100. Greenberg J, Losee R, Agüera JRP, et al. HIVE: Helping interdisciplinary vocabulary engineering. Bulletin of the American Society for Information Science and Technology. 2011;37(4):23-26.

101. Palmer CL. Work at the Boundaries of Science: Information and the Interdisciplinary Research Process. Netherlands: Kluwer Academic Publisher; 2001. 